НАУКОВИЙ ВІСНИК

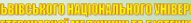

Cientific messegger of Livi National University
Veterinary Meedicine and Biotechnologies

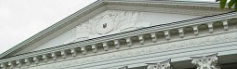

तो गे है

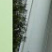

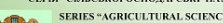

Tом 21 № 91

2019
Науковий вісник Дьвівського національного університету ветеринарної медицини та біотехнологій імені С.3. Гжицького. Серія: Сільськогосподарські науки

Scientific Messenger of Lviv National University of Veterinary Medicine and Biotechnologies. Series: Agricultural sciences

ISSN 2519-2698 print

https://nvlvet.com.ua/index.php/agriculture

doi: 10.32718/nvlvet-a9105

UDC 636.32/38:591.16.612.063

\title{
The sexual activity of the ram-sires, depending on their mode of use
}

\author{
K. Hrymak \\ Institute of Animal Biology NAAS, Lviv, Ukraine
}

Article info

Received 04.09.2019

Received in revised form 04.10 .2019

Accepted 05.10.2019

Institute of Animal Biology NAAS, V. Stus Str., 38, Lviv,

79034, Ukraine.

Tel.: +38-093-235-95-55

E-mail:phm89@ukr.net
Hrymak, K. (2019). The sexual activity of the ram-sires, depending on their mode of use. Scientific Messenger of Lviv National University of Veterinary Medicine and Biotechnologies. Series: Agricultural sciences, 21(91), 29-32. doi: $10.32718 /$ nvlvet-a9105

Literary data are presented and their analysis is conducted regarding the mode of use of ram-sires and their effect on sexual activity and sperm productivity. The results of research of scientists with recommendations of optimal modes of use of fetuses for semen production and its cryopreservation in nonpairing and steaming periods are presented. According to the results of the analysis of many researchers, the activity of the sexual reflexes of the rams in the spring and summer decreases by 1.4 times compared to the winter. At the same time quantitative indicators of sperm productivity decrease. However, M.M. Aibazov (1987) experimentally confirmed that sheep-breeders of the Caucasian fine-breed and Australian merenos breed exhibit high sexual activity and produce sperm of satisfactory quality in all seasons. Similar results were obtained by British researchers in the study of sexual activity and sperm productivity of ram-sires of British breeds. A.A. Ivanov (1987) indicates the regime of use of ram sires, for five years with obtaining and subsequent freezing in the unpaired period 6 ejaculates (2 doublets 3 times) per week and in the breeding season 10 ejaculates (2 doublets 5 times) week. P.P. Kundyshev (2004) considers it possible and proposes to obtain from the breeding rams for cryopreservation and storage during the year, both unpaired and steaming periods, with daily ejaculate production. This mode, according to the author, provides a sufficiently high fertility sperm up to 50.3 percent. In the study of sexual activity and sperm productivity of ram-sires of different breeds, including the North Caucasian meat-wool, jalgin merino, Soviet merino, maniche merino, Russian meat merino, Edelbaev, polldore P.P. Mammoth and others. (2018) found that the most active were the rams of the Edinburgh breed, which took 22 seconds. ejaculate secretion, and the slowest texel breeders, which took 39 seconds to ejaculate. The rams of the other breeds listed above spent 25 to 34 seconds to ejaculate. In addition, rams of Texel breed produced the lowest activity sperm, and therefore only 19 sperm were frozen from one ejaculate, with an average of 20 to 26 sperm species tested.

Key words: rams, sperm productivity, seasonal activity, cryopreservation.

\section{Статева активність баранів-плідників залежно від режиму їх використання}

\author{
Х.М. Гримак
}

Інститут біології тварин НААН, м. Львів, Украӥна

Наведено літературні дані та проведено їх аналіз щзодо режиму використання баранів-плідників і його впливу на статеву активність і спермопродуктивність. Викладено результати досліджень вчених з рекомендаціями оптимальних режимів використання плідників для одержання сперми та ї̈ кріоконсервування у непарувальний $і$ парувальний періоди. За результатами аналізу багатьох дослідників активність статевих рефлексів баранів-плідників у весняний і літній періоди знижується у 1,4 разу порівняно із зимовим. Одночасно змениуються кількісні показники спермопродуктивності. Проте, М.М. Айбазов (1987) експериментально підтвердив, щзо барани-плідники кавказької тонкорунної і породи австралійський меренос виявляють високу статеву активність і продукують сперму задовільної якості у всі періоди року. Аналогічні результати отримано англійськими дослідниками при вивченні статевої активності та спермопродуктивності баранів-плідників британських порід. А.А. Іванов (1987) вказує на режсм використання баранів-плідників, протягом n'яти років з одержанням $i$ подальшим заморожуванням у непарувальний період 6 еякулятів (2 дуплетні садки 3 рази) на тиждень та у парувальний сезон 10 еякулятів (2 дуплетні садки 5 разів) на тиждень. П.П. Кундишев (2004) вважає можливим і пропонує протягом року як у непарувальний, так $i$ в парувальний періоди одержувати 
від баранів-плідників для кріоконсервування $і$ зберігання за щзоденного режиму використання з отриманням двох еякулятів. Такий режим, на думку автора, забезпечує достатньо високу запліднювальну здатність сперми до 50,3 відсотка. При дослідженні статевої активності та спермопродуктивності баранів-плідників різних порід, зокрема північнокавказької м'ясо-вовнової, джалгинського мериноса, радянського мериноса, маничського мериноса, російського м'ясного мериноса, едильбаївської, поллдореста, тексель П.П. Мамонтовою та ін. (2018) виявлено, щзо найактивнішими були барани едильбаївської породи, які затрачали 22 сек. на виділення еякуляту, а найповільнішими плідники породи тексель, які затрачали на еякулят 39 секунд. Барани-плідники інших вищеперерахованих порід затрачали на виділення еякуляту від 25 до 34 секунди. Крім того, барани породи тексель продукували сперму найнижчої активності, у зв'язку з тим із одного еякуляту заморожували лише 19 спермодоз за середньої кількості досліджуваних порід від 20 до 26 спермодоз.

Ключові слова: барани, спермопродуктивність, сезонна активність, кріоконсервування.

Результативність ведення галузі вівчарства у значній мірі визначається ефективною селекційноплемінною роботою та широким застосуванням біотехнологічних методів відтворення, зокрема штучного осіменіння вівцематок деконсервованою спермою (Gordon, 1988; Karagiannidis et al., 2000; Magomedov, 2008). У цьому аспекті важливого значення надається інтенсивному використанню високоцінних баранівплідників 3 метою максимального одержання у різні періоди сезонної активності високоякісної біологічно повноцінної сперми. Бо саме від баранів на 80\% залежить якість приплоду та обсяг майбутнього поголів'я. Відомо, що у баранів сперматогенез і секреція гормону тестостерону за отимальних умов утримання догляду та повноцінної годівлі здійснюється безперервно. Вияв статевих рефлексів теж буває у всі сезони року. Проте інтенсивність сперматогенезу в різні періоди сезонної активності залежать від режиму використання баранів-плідників, генотипових та фенотипових чинників (Wayne et al., 1990; Notter, 2002; Moghadam et al., 2012; Marti et al., 2012; Benia et al., 2013; Amrane et al., 2013).

Статева активність баранів залежить не тільки від маси тіла і загального розвитку, а й від нервовоконституційних типів. Академік І.П. Павлов (Pavlov \& Asratyan, 1973) за швидкістю утворення і стійкістю умовних статевих рефлексів поділив тварин на чотири типи: холерик, сангвінік, флегматик, меланхолік. Швидкість здійснення статевих рефлексів, інтенсивність секреції додаткових статевих залоз - міхурцеподібної, простати і цибулинних та динаміка просування сперміїв у ампули сім'япроводів залежить від фізіологічного тонусу організму і реактивності сексуальних центрів (Lopyrin, 1971).

Ряд дослідників у різні часи вивчали вплив сезону року на статеву активність. Так, за даними В.К. Рабочева (Rabochev et al., 1992) статева функція баранівплідників в умовах Північного Кавказу значно знижується посеред зими, а особливо у спекотні літні місяці. Ідентичні результати отримано У.К. Избасаровым (Izbasarov, 1970), П.И. Ледневым (Lednev, 1972) за аналізу статевої активності баранів каракульської породи та аборигенної кордючної породи Ташкенської області.

А.М. Асланян, О.И. Лисовая (Aslanyan \& Lisovaya, 1963) вказують, що барани асканійської породи в осінній період затрачали дещо менше часу (в середньому 13-19 сек) на кожну садку порівняно 3 літнім періодом.
Дослідженнями А.Д. Курбатова, Е.М. Платова та ін. (Kurbatov et al., 1988) встановлено, що найбільше відмов від садок у баранів спостерігалося навесні, а найменше зимою. Аналогічні дані отримали D. Tully, P. Burfening (Tulley \& Burfening, 1983), якими виявлено, що найвищу статеву активність барани-плідники виявляли восени і зимою в умовах короткого світлового дня. За штучного скорочення світлового дня статева активність плідників була значно вищою порівняно з утриманням баранів у звичайних умовах.

За результатами аналізу багатьох дослідників активність статевих рефлексів баранів-плідників у весняний і літній періоди знижується у 1,4 разу порівняно із зимовим. Одночасно зменшуються кількісні показники спермопродуктивності. Проте, М.М. Айбазов (Aybazov, 1986) експериментально підтвердив, що барани-плідники кавказької тонкорунної i породи австралійський меренос виявляють високу статеву активність і продукують сперму задовільної якості у всі періоди року. Аналогічні результати отримано англійськими дослідниками при вивченні статевої активності та спермопродуктивності баранівплідників британських порід (Gordon, 1988).

Ряд авторів, зокрема Н.В. Логинова та ін. (Loginova et al., 1966); В.М. Давиденко та ін. (Davidenko et al., 1979); Н.А. Желтобрюк і ін. (Zheltobryukh et al., 1985) вказують на можливість використання високопродуктивних баранів-плідників у непарувальний період. Однак, питання оптимального режиму використання високоцінних плідників протягом року почали вивчати 3 середини 80-х років минулого століття - із розробленням і впровадженням у виробництво технології глибоко заморожування сперми баранів.

Доведено, що активність сперматогенезу і вияв статевих рефлексів у баранів варіює в широких межах, і це залежить в основному від режиму використання (Zheltobryukh \& Nikitin, 2000). М.М. Айбазовим (Aybazov, 1986; 2003) було апробовано три режими використання баранів-плідників. Протягом шести місяців (з січня по червень) від баранів одержували по 6, 8, i 10 еякулятів у тиждень, дуплетними садками. У результаті проведених досліджень встановлено, що за навантаження 10 садок на тиждень об'єм еякуляту за вказаний період зменшився на 47\%, за вісьмох - 43\% та за шістьох лише на 9 відсоків. Значне зниження об'єму еякуляту за навантаження 8 і 10 садок на тиждень автори виявляли в останні два місяці досліду.

Внаслідок проведених експериментальних досліджень M.M. Айбазов (Aybazov, 2003) рекомендує використовувати баранів-плідників протягом року для 
нагромадження глибокозамороженої сперми 3 навантаженням 6 еякулятів (три дуплетні садки) на тиждень. Такий режим навантаження дає можливість заготовити 4-4,5 тисячі спермодоз, тим самим у 2-3 рази підвищити інтенсивність використання високоцінних плідників.

Подібний режим використання для взяття сперми баранів-плідників запропонували В. Давиденко, I. Шинкаренко, О. Ігнатенко (Davidenko et al., 1981). Ними встановлено, що при щоденному одержанні двох еякулятів властивість сперміїв до кріоконсервування достовірно знижується порівняно з отриманням через дві доби. Автори вважають оптимальним режимом для одержання і заморожування сперми у непарувальнй період 6 еякулятів (дві триплетні садки).

Однак деякі дослідники рекомендують інтенсивніше використовувати високоцінних баранівплідників протягом року для нагромадження глибокозамороженої сперми. Так, В.М. Боярский (Boyarskiy, 1980), Т.I. Ліацкепладзе (Liatskepladze, 1982) пропонують від висококласних плідників цілорічно одержувати по десять еякулятів у тиждень (2 еякуляти протягом 5 днів).

A.А. Іванов (Ivanov, 1987) вказує на режим використання баранів-плідників, протягом п'яти років 3 одержанням і подальшим заморожуванням у непарувальний період 6 еякулятів (2 дуплетні садки 3 рази) на тиждень та у парувальний сезон 10 еякулятів (2 дуплетні садки 5 разів) на тиждень.

П.П. Кундишев (Kundyshev, 2004) вважає можливим і пропонує протягом року як у непарувальний, так і в парувальний періоди одержувати від баранівплідників для кріоконсервування і зберігання за щоденного режиму використання 3 отриманням двох еякулятів. Такий режим, на думку автора, забезпечує достатньо високу запліднювальну здатність сперми до 50,3 відсотка.

При дослідженні статевої активності та спермопродуктивності баранів-плідників різних порід, зокрема північнокавказької м'ясо-вовнової, джалгинського мериноса, радянського мериноса, маничського мериноса, російського м'ясного мериноса, едильбаївської, поллдореста, тексель П.П. Мамонтовою та ін. (Mamontova, 2018) виявлено, що найактивнішими були барани едильбаївської породи, які затрачали 22 секунди на виділення еякуляту, а найповільнішими плідники породи тексель, які затрачали на еякулят 39 секунд. Барани-плідники інших вищеперерахованих порід затрачали на виділення еякуляту від 25 до 34 секунди. Крім того, барани породи тексель продукували сперму найнижчої активності, у зв'язку з тим iз одного еякуляту заморожували лише 19 спермодоз за середньої кількості досліджуваних порід від 20 до 26 спермодоз.

\section{Висновки}

Таким чином, у літературних джерелах подано суперечливі дані щодо статевої активності та використання баранів-плідників. Це вказує на доцільність детальнішого вивчення режимів використання високоцінних баранів для встановлення оптимального режиму одержання біологічно активної сперми з метою їі кріоконсервування та подальшого використання для штучного осіменіння овець.

\section{References}

Amrane, A.A., Hammoudi, S.M., Belhamiti, B.T., Selles, S.M.A., Benia, A.R., \& Kaidi, R. (2013). Seasonal variation of plasma testosterone levels in Algerian male Arabia goats. African Journal of Biotechnology, 12(48), 6785-6790. doi: 10.5897/AJB2013.12131.

Aslanyan, M.M., \& Lisovaya, O.I (1963). Kharakteristika kachestvennykh i kolichestvennykh pokazateley semeni baranov askaniyskoy porody po sezonam goda [Characteristics of the qualitative and quantitative indicators of the seed of rams of Ascanian breed by season of the year]. Razvedeniye ovets, 11, 67-80 (in Russian).

Aybazov, A.-M.M. (1986). Ratsionalnoe ispolzovaniye vysokotsennykh baranov-proizvoditeley [Rational use of high-value ram-producers]. Tezisy nauchnykh soobshcheniy nauchno-proizvodstvennoy konferentsii po ovtsevodstvu i kozovodstvu. VNIIOK. Stavropol, 119-120 (in Russian).

Aybazov, A.M.M. (2003). Teoreticheskiye osnovy. razrabotka i sovershenstvovaniye biotekhnologicheskikh metodov vosproizvodstva ovets [Theoretical foundations, development and improvement of biotechnological methods of sheep reproduction] (Doctoral dissertation. Stavropolskiy nauchno-issledovatelskiy institut zhivotnovodstva i kormoproizvodstva) (in Russian).

Benia, A.R., Taibi, K., Ait-Amrane, A., Belhamiti, T., Hammoudi, S.M., \& Kaidi, R. (2013). Study of seasonal sexual activity variations in Algerian rams: Sexual behaviour, testosterone concentration control and environmental factors. African Journal of Biotechnology, 12(41), 6042-6048. doi: 10.5897/AJB2013.12172.

Boyarskiy, V.M. (1980). Izucheniye vliyaniya sezonnykh faktorov na semya baranov s tselyu razrabotki metoda kruglosutochnogo nakopleniya zapasov biologicheski polnotsennogo semeni $\mathrm{V}$ zamorozhenom vi$\mathrm{de}$ [Studying the influence of seasonal factors on sheep semen in order to develop a method of round-theclock accumulation of stocks of biologically valuable semen in frozen form]: Avtoref. diss. kand. biol nauk. Dubrovody (in Russian).

Davidenko, V.M., Shinkarenko, I.S., \& Ignatenko, O.I. (1981). Rezhimy ispolzovaniya baranov i ustoychivost semeni pri zamorazhivanii i ottaivanii [Modes of use of rams and semen resistance during freezing and thawing] Zhivotnovodstvo, 9, 48-49 (in Russian).

Davydenko, V.M. (1979). Spermoproduktsiia baraniv askaniiskoi tonkorunnoi porody zalezhno vid sezonnykh i meteorolohichnykh faktoriv [Sperm production of sheep of the Ascani fine-fleece breed is fallow of seasonal and meteorological factors]. Vivcharstvo Respublikanskyi mizhvidomchotematychno naukovyi zbirnyk, 18, 94-100 (in Ukrainian).

Gordon, A. (1988). Kontrol vosproizvodstva selskokhozyaystvennykh zhivotnyk [Reproduction control of 
farm animals] M.: Agropromizdat, 10-24 (in Russian).

Ivanov, A.A. (1987). Vnedryaem novoyu tekhnologiyu osemeneniya [Introducing a new insemination technology]. Ovtsevodstvo, 2, 34-36 (in Russian).

Izbasarov, U.K. (1970) Fiziologicheskiye i biokhimicheskiye pokazateli karakulskikh baranov po sezonam goda [Physiological and biochemical parameters of Karakul sheep by season of the year] Tr. VNII karakulevodstva, 19, 216-219 (in Russian).

Karagiannidis, A., Varsakeli, S., Alexopoulos, C., \& Amarantidis, I. (2000). Seasonal variation in semen characteristics of Chios and Friesian rams in Greece. Small Ruminant Research, 37(1-2), 125-130. doi: 10.1016/S0921-4488(99)00143-1.

Kundyshev, P.P. (2004) Intensivnost ispolzovaniya baranov pri zamorazhivanii ikh semeni i estestvennoy sluchke [Intensity of use of rams when freezing their semen and natural mating]. Ovtsy. kozy. sherstnoe delo, 2, 21-25 (in Russian).

Kurbatov, A.D., Platov, E.M., Korban, N.V., Moroz, L.G., \& Nauk, V.A. (1988). Kriokonservatsiya spermy selskokhozyaystvennykh zhivotnykh [Cryopreservation of sperm of farm animals]. Leningrad. Agropromizdat (in Russian).

Lednev, P.I. (1972). Sezonnye izmeneniye spermoproduktsii baranov v usloviyakh predgornoy zony Tashkentskoy oblasti[Seasonal change in sperm production of sheep in the foothill zone of the Tashkent region]: Avtoref. dok. kand. biol. nauk. Dushanbe (in Russian).

Loginova, N.V., Donskaya, V.I., Rak, L.P. (1966). Sinkhronizatsiya okhoty u ovets [Sheep hunting synchronization]. Zhivotnovodstvo, 9, 70-74 (in Russian).

Lopyrin, A.I. (1971). Biologiya razmnozheniya ovets [Biology of sheep breeding.]. M.: Kolos (in Russian).

Liatskepladze, T.I. (1982). Glubokoe zamorazhivaniye semeni baranovi imeretinskoy porody i puti ispolzovaniya ego dlya sozdaniya porod intensivnogo tipa[Deep freezing of a ram semen of an Imereti breed and ways to use it to create intensive-type breeds]: Avtoref. diss. kand. biol. Nauk. Dubrovody (in Russian).

Magomedov, Z.Z. (2008). Ratsionalnoe ispolzovaniye vysokotsennykh importnykh Baranov [Rational use of high-value imported sheep]. In Doklady Rossiyskoy akademii selskokhozyaystvennykh nauk, 3, $42-48$ (in Russian).

Mamontova, T.V. (2018). Sravnitelnaya kharakteristika polovoy aktivnosti. urovnya spermoproduktsii i ustoychivost $\mathrm{k}$ kriokonservatsii spermy baranov razlichnykh porod [Comparative characteristics of sexual activity. sperm production level and resistance to cryopreservation of sperm of sheep of various breeds]. Izvestiya Orenburskogo gosudarstvennogo agrarnogo universitet, 1(69), 145-147 (in Russian).

Martí, J.I., Aparicio, I.M., Leal, C.L.V., \& García-Herreros, M. (2012). Seasonal dynamics of sperm morphometric subpopulations and its association with sperm quality parameters in ram ejaculates. Theriogenology, 78(3), 528-541. doi: 10.1016/j.theriogenology.2012.02.035.

Moghaddam, G.H., Pourseif, M.M., \& Rafat, S.A. (2012). Seasonal variation in semen quantity and quality traits of Iranian crossbred rams. Slovak journal of animal science, 45(3), 67-75.

Notter, D.R. (2002). Opportunities to reduce seasonality of breeding in sheep by selection. Sheep Goat Res J, 17(3), 21-32.

Pavlov, I.P., \& Asratyan, E.A. (1973). Dvadtsatiletnii opty obektivnogo izucheniya vysshei nervnoi deyatelnosti (povedeniya) zhivotnykh. [Twenty years of experience in the objective study of higher nervous activity (behavior) of animals] Nauka (in Russian).

Rabochev, V.K., Aybazov, A.-M.M., Kunizhev, M.M. (1992). Razrabotka sistemy ratsionalnogo ispolzovaniya vysokotsennykh baranov-proizvoditeley i ovtsematok [Development of a system for the rational use of high-value sheep-producers and ewes] Mat. nauch.-proizv. konf po ovtsevodstvu i kozovodstvu VNIIOK. Stavropol, 52-62 (in Russian).

Tulley, D., \& Burfening, P.J. (1983). Libido and scrotal circumference of rams as affected by season of the year and altered photoperiod. Theriogenology, 20(4), 435-448. doi: 10.1016/0093-691x(83)90203-0.

Wayne, N.L., Malpaux, B., \& Karsch, F.J. (1990). Photoperiodic requirements for timing onset and duration of the breeding season of the ewe: synchronization of an endogenous rhythm of reproduction. Journal of Comparative Physiology A, 166(6), 835-842. doi: 10.1007/BF00187330.

Zheltobryukh, N.A., \& Nikitin, V.Ya. (2000). Ratsionalnoe ispolzovanme vysokotsennykh baranov [Rational use of high-value rams]. Vosproizvodstvo ovets. Stavropol (in Russian).

Zheltobryukh, N.A., Ivakhnenko, V.K., \& Aybazov, A.M.M (1985). Vliyaniye sezonnykh faktorov i rezhima ispolzovaniya na spermoproduktsiyu baranov [The influence of seasonal factors and mode of use on rams sperm production ]. Zhivotnovodstvo, 3, 44-46 (in Russian). 